\title{
Computational Fluid Dynamics Modelling and Analysis Approach for Estimating Internal Short-Circuiting in Clearwells
}

\author{
Eunher Shin ${ }^{1}$, Jewan Ryu ${ }^{2}$ and Heekyung Park ${ }^{2, *}$ \\ 1 K-Water Research Institute, K-Water, Yuseong-daero 1689beon-gil, Yuseong-gu, Daejeon 34350, Korea; \\ shin2@kwater.or.kr \\ 2 Department of Civil and Environmental Engineering, Korea Advanced Institute of Science and Technology, \\ Daejeon 34141, Korea; rjw0421@kaist.ac.kr \\ * Correspondence: hkpark@kaist.ac.kr; Tel.: +82-42-350-7170
}

check for updates

Citation: Shin, E.; Ryu, J.; Park, H. Computational Fluid Dynamics Modelling and Analysis Approach for Estimating Internal Short-Circuiting in Clearwells. Water 2021, 13, 1849. https://doi.org/10.3390/w13131849

Academic Editor:

Armando Carravetta

Received: 3 May 2021

Accepted: 30 June 2021

Published: 3 July 2021

Publisher's Note: MDPI stays neutral with regard to jurisdictional claims in published maps and institutional affiliations.

Copyright: (c) 2021 by the authors. Licensee MDPI, Basel, Switzerland. This article is an open access article distributed under the terms and conditions of the Creative Commons Attribution (CC BY) license (https:// creativecommons.org/licenses/by/ $4.0 /)$.

\begin{abstract}
Disinfection is an effective microorganism inactivation method that has contributed historically to decreasing waterborne diseases. It is necessary to improve hydraulic efficiency for ensuring disinfection ability without creating disinfection by-products. However, many hydraulic efficiency indices, which are a type of black-box analyses based on residence time distribution curves, have been used to assess short-circuiting and mixing. We propose a novel index (internal short-circuiting index, ISI) and analysis approach (internal short-circuiting estimation method, ISEM) based on computational fluid dynamics (CFD) modelling for understanding the local hydrodynamics. Then, we implement ISEM to quantify the effect of the clearwell configuration with the different lengthto-width and shape ratios on the hydraulic efficiency. As the hydraulic efficiency surrogated by $\mathrm{T}_{10} / \mathrm{T}$ converges to the maximum value, the ISI values at inlet and outlet reduce rapidly, and the recirculation and dead zones shrink in the channel zones. Thus, the ISI curve changes from a V shape to U shape. The ISEM demonstrates that it is applicable under various conditions and it enables engineers to design clearwells for optimizing the disinfection ability. Furthermore, the CFD model in this study can be combined with machine learning techniques in future studies to extract knowledge for reducing the computational cost.
\end{abstract}

Keywords: clearwell; internal short-circuiting estimation method (ISEM); computational fluid dynamics; length-to-width ratio; shape ratio; machine learning

\section{Introduction}

Disinfection is an essential and effective microorganism inactivation method that has historically contributed to decrease waterborne diseases. This process occurs through contact with suitable disinfectant concentration and sufficient time for microorganisms to be inactivated in the clearwell. However, a large disinfectant dosage will inflate operational costs and induce high concentrations of disinfection by-products (DBPs) such as trihalomethanes and haloacetic acids. The CT concept was introduced in the United States to meet the required pathogen inactivation level [1]. The computed CT values, where $\mathrm{C}[\mathrm{mg} / \mathrm{L}]$ denotes the residual disinfectant concentration and $\mathrm{T}[\mathrm{min}]$ represents contact time $\mathrm{T}_{10}$ when $10 \%$ of a tracer is out of the clearwell after injecting the tracer at the inlet, are compared with reference values for given pathogens to assess whether the required level of inactivation has been accomplished. Although the CT method represents a conservative disinfection ability because it only considers disinfectant concentration at the outlet, and it uses the $\mathrm{T}_{10}$ value as a hydraulic estimation index, this method is accepted and applied worldwide. Increasing the $\mathrm{C}$ value to meet the required $\mathrm{CT}$ value is not recommended because a high $C$ value can increase the potential for forming DBPs. Thus, improving the hydraulic efficiency surrogated by $\mathrm{T}_{10}$ is a widely recommended option to increase the disinfection ability and reduce the disinfection dosage and DBPs. Plug flow is an optimal 
hydrodynamic condition at which disinfection performance is maximized [2-4]. However, the flow pattern inside the clearwell deviates from the ideal pattern because of the short-circuiting and mixing phenomena. This implies that both reducing short-circuiting and increasing mixing in the clearwell are the two main goals for improving the overall disinfection ability. Inside the clearwell, recirculation zones where the disinfectants are retained and mixed for a certain period and high-velocity jet zones are formed because of the viscous and turbulent effects. These zones cause some injected disinfectants to pass through a clearwell quicker than the theoretical hydraulic retention time (HRT); other disinfectants are trapped and retained for an extended period.

The accurate prediction of hydrodynamics within the clearwell is fundamental to provide convincing disinfection performances and harness the disinfection ability. Therefore, the computational fluid dynamics (CFD) model has been widely used to simulate flow conditions and mixing processes during the operation of clearwell since the late 1990s. A majority of the CFD models were developed for analyzing hydrodynamics and conservative tracer transport to derive a residence time distribution (RTD) curve [5-14]. Such computational models have been demonstrated to be a powerful and efficient approach as an alternative to physical experiments at a considerably lower cost. Recently, the advanced CFD model considers disinfectant decay, pathogen inactivation, and DPBs formation and hydraulic characterization in the disinfection process through the incorporation of mathematical formulation representing kinetic processes and interactions [15-24]. Researchers can predict the removal of chemicals or pathogens directly by adopting this approach The implementation of an appropriate turbulence model is an important issue in CFD simulations because the employed turbulence model has a significant effect on modelling accuracy. Reynolds-averaged Navier-Stokes equation (RANS) is popular as a turbulent model because this simulation resolves only the mean flow and conducts good hydraulic performance with cost-effectiveness [25-27]. Recently, large eddy simulation (LES), which is an intermediate approach between directed numerical simulation and RANS, has gained significant attention with the improvement of computer performance $[12,28,29]$. The LES is shown to be more reliable and realistic than RANS because of its ability to better predict the spatial transition to turbulence characterizing the flow. New data-driven machine learning methods to improve the RANS are suggested in recent years. [30,31]. These researches demonstrated that machine learning techniques could extract knowledge from the CFD data and support to reduce the computational cost.

Several indices are suggested to interpret the hydraulic performance of physical experiments or CFD simulations [2,27,32,33]. These indices are called hydraulic efficiency indicators (HEIs), and they can be classified into short-circuiting and mixing indices. The short-circuiting indices include initial arrival time $\left(\mathrm{T}_{\mathrm{i}}\right), 10 \%$ arrival time $\left(\mathrm{T}_{10}\right)$, maximum concentration arrival time $\left(\mathrm{T}_{\mathrm{p}}\right)$, mean residence time $\left(\mathrm{T}_{\mathrm{g}}\right)$, and baffling factor $\left(\mathrm{T}_{10} / \mathrm{T}\right)$, which is the ratio of $\mathrm{T}_{10}$ and theoretical HRT. Dispersion index $\left(\sigma^{2}\right)$, Morril index $\left(\mathrm{T}_{90} / \mathrm{T}_{10}\right)$, and $90 \%$ arrival time $\left(T_{90}\right)$ can be regarded as mixing indices. Among these indices, the baffling factor is commonly used for quantifying disinfection credits because it can be directly used to calculate the CT value. These HEIs are extracted from the normalized RTD (E-curve) and normalized cumulative RTD plots (F-curve). Although the RTD curve is useful information, it is based on monitored injected tracer concentration at the inlet and residual tracer concentration at the outlet. This implies that implementing HEIs originating from RTD in a clearwell design is a black-box approach; this evaluation methodology cannot represent internal hydraulics and kinetic characteristics in the clearwell.

Therefore, this study was initiated to propose a novel index (internal short-circuiting index, ISI) and analysis approach (internal short-circuiting estimation method, ISEM) based on the CFD simulation results for clarifying local hydrodynamics inside the clearwell. Furthermore, using ISEM, we inquired and quantified the effect of the clearwell configuration on the hydraulic efficiency. A total of 18 cases with different length-to-width (LW) ratios and shapes were simulated and analyzed. The paper is structured as follows. First, we develop the CFD model and explain how to implement the ISEM. Then, in Sections 3 and 4, 
the findings are discussed. We conclude by highlighting the advantages and applicability of the proposed method.

\section{Materials and Methods}

\subsection{Developing, Verifying, and Simulating the CFD Model}

The governing equations of the CFD model were the mass conservation equation for incompressible flow (i.e., continuity equation) and momentum conservation equation (i.e., Navier-Stokes equations):

$$
\begin{gathered}
\frac{\partial \overline{u_{i}}}{\partial x_{i}}=0, \\
\frac{\partial \overline{u_{i}}}{\partial t}+\overline{u_{j}} \frac{\partial \overline{u_{i}}}{\partial x_{j}}=-\frac{1}{\rho} \frac{\partial \bar{p}}{\partial x_{j}}+\frac{\partial}{\partial x_{j}}\left(v \frac{\partial \overline{u_{i}}}{\partial x_{j}}-\overline{u_{i}^{\prime} u_{j}^{\prime}}\right),
\end{gathered}
$$

where $\mathrm{u}_{\mathrm{i}}$ is the velocity components in the $\mathrm{i}$-direction $(\mathrm{x}, \mathrm{y}$, and $\mathrm{z}$-direction), $\mathrm{p}$ is the pressure, $t$ is the time, $\rho$ is the fluid density, and $x_{i}$ and $x_{j}$ represent Cartesian coordinates. The overbar means the averaged component. A $\mathrm{k}-\varepsilon$ model and a first-order upwind scheme were used as a turbulence model and numerical scheme to approximate the effective stresses and advective terms. Conservative tracer transport was analyzed using the advection-diffusion equation:

$$
\frac{\partial \bar{C}}{\partial t}+\overline{u_{j}} \frac{\partial \bar{C}}{\partial x_{j}}=\frac{\partial}{\partial x_{j}}\left(D_{t} \frac{\partial \bar{C}}{\partial x_{j}}\right)
$$

where $D_{t}$ is the turbulent diffusivity and is calculated from the ratio of the turbulent viscosity $v_{t}$ to the Schmidt number. In this study, the Schmidt number was set to 0.7 . In the developed model, disinfection kinetics such as disinfectants decay, pathogens inactivation, and DBPs formation were not considered because this research was focused on developing the novel local hydraulic efficiency indicator and estimation method. A no-slip condition was given for the wall, and a free-slip condition was set for the surface water condition. We simulated the model with more than 100,000 tetra meshes. Other setup conditions and assumptions for the CFD model are listed in Table 1. The CFD model was first implemented with a random initial condition in a steady state; the unsteady transport of the tracer was simulated in this fluid flow. Then, the E- and F-curves were calculated, and the $\mathrm{T}_{10} / \mathrm{T}$ value was derived. The CFD modeling in this study was implemented using a commercial CFD code.

Table 1. Setup conditions and assumptions of the developed CFD model.

\begin{tabular}{cccc}
\hline Items & Condition & Items & Condition \\
\hline Fluid & Pure water $\left(25^{\circ} \mathrm{C}\right)$ & Wall conditions & No-slip condition \\
Turbulence model & $\mathrm{k}-\boldsymbol{\varepsilon}$ model & Condition of water surface & Free-slip condition \\
Heat transfer & Tot considered & Mesh & 50 times \\
$\begin{array}{c}\text { Fluctuation of flow rate } \\
\text { and water depth }\end{array}$ & None & Iteration no. & $30 \mathrm{~s}$ \\
Inlet flow direction & Perpendicular & Result reporting time step & Target residual $<10^{-3}$ \\
Pressure at outlet & $1 \mathrm{~atm}$ & Convergence condition & \\
\hline
\end{tabular}

The hydrodynamics and tracer transport of the developed CFD model were verified using an acoustic doppler velocimeter (ADV) and tracer tests in pilot-scale, as shown in Figure 1. The first experiment was designed to verify local hydrodynamics similarity between the CFD model and the pilot test in the second, third, fourth, and fifth channel zones of the Type III shape with six baffles illustrated in Figure 1 and Table 2. We measured instantaneous velocities with ADV sampling at $10 \mathrm{~Hz}$ for $180 \mathrm{~s}$. The second test was used to certify the tracer transport by comparing the $\mathrm{T}_{10} / \mathrm{T}$ values of the CFD model and the pilot tests. Sodium fluoride $(\mathrm{NaF})$ was used as a tract. Slug method (i.e., pulse input method), which dumps the tracer at once, was used. Sampling was performed every $3 \mathrm{~min}$ 
for a total of $60 \mathrm{~min}$ at the outlet. Then, fluorine concentration was analyzed. A total of 12 pilot test cases were performed in Types I and III shapes with different LW ratios. LW ratio, the length-to-width ratio, can estimate the baffling factor $\left(\mathrm{T}_{10} / \mathrm{T}\right)$ where length is the longest flow path (red dash line) and width is the average channel width for each flow path, as shown in Figure 2. Three different shapes called Types I, II, and III were simulated to investigate the factors that increase $\mathrm{T}_{10} / \mathrm{T}$ as the $\mathrm{LW}$ ratio increases and the effect of shape on the pattern of the $\mathrm{LW}$ ratio and $\mathrm{T}_{10} / \mathrm{T}$. As shown in Figure 2, Type I is a rectangle (length $=1.724 \mathrm{~m}$ and width $=3.448 \mathrm{~m}$ ); type II is a square (side $=2.438 \mathrm{~m}$ ); and Type III is also a rectangle (length $=3.448 \mathrm{~m}$ and width $=1.724 \mathrm{~m}$ ). The shape ratios of Types I, II, and III are calculated by dividing the length with the width, and they are $0.5,1$, and 2 , respectively. A water depth of $0.305 \mathrm{~m}$ and a flow rate of $77.87 \mathrm{~L}$ per minute were used for all simulations. The theoretical detention time of each type was the same. As explained in Table 2, we simulated a total of 18 cases with different LW ratios for Types I, II, and III.
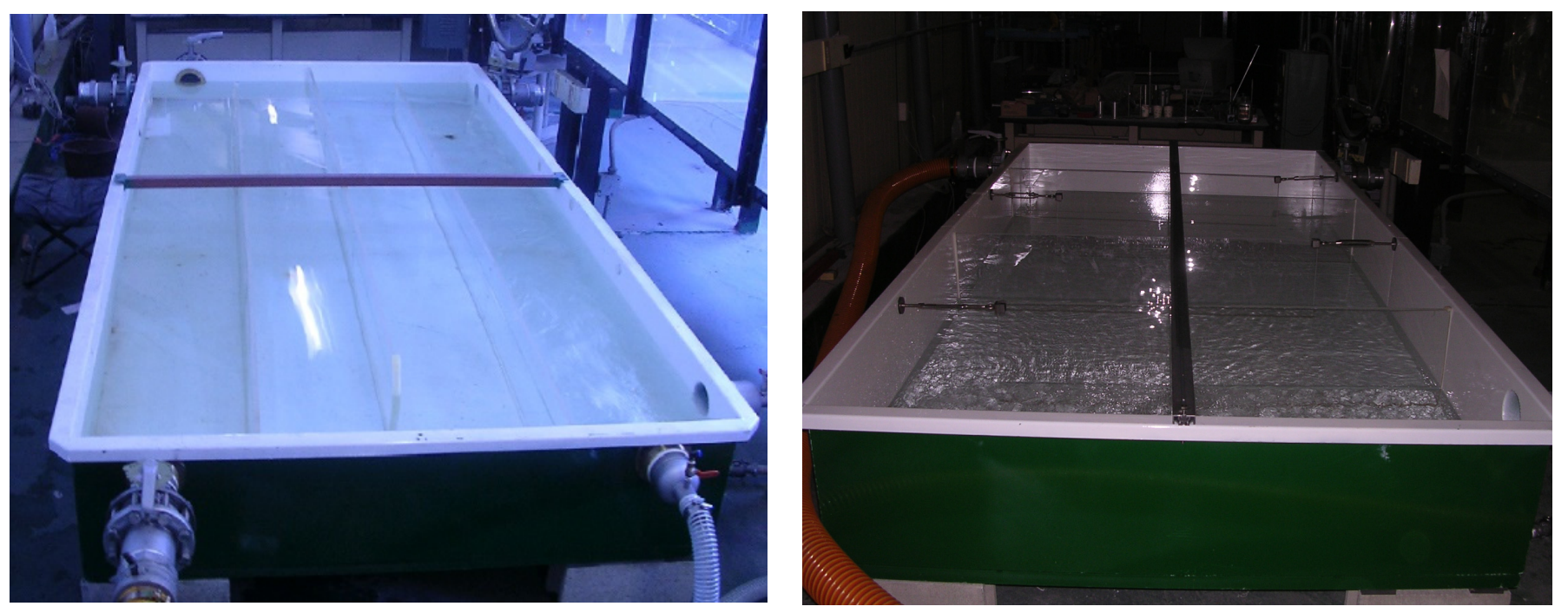

Figure 1. Pilot plant for CFD model verification.

Table 2. Cases of CFD simulations.

\begin{tabular}{cccccc}
\hline Type & Number of Baffles & LW Ratio & Type & Number of Baffles & LW Ratio \\
\hline Type I & 1 & 9 & Type II & 7 & 64 \\
& 2 & 20 & Type III & 3 & 11 \\
& 3 & 34 & & 4 & 16 \\
Type II & 4 & 52 & & 5 & 22 \\
& 2 & 9 & & 6 & 29 \\
& 3 & 25 & & 7 & 37 \\
& 4 & 36 & & 9 & 46 \\
& 5 & 49 & & 10 & 66 \\
\hline
\end{tabular}




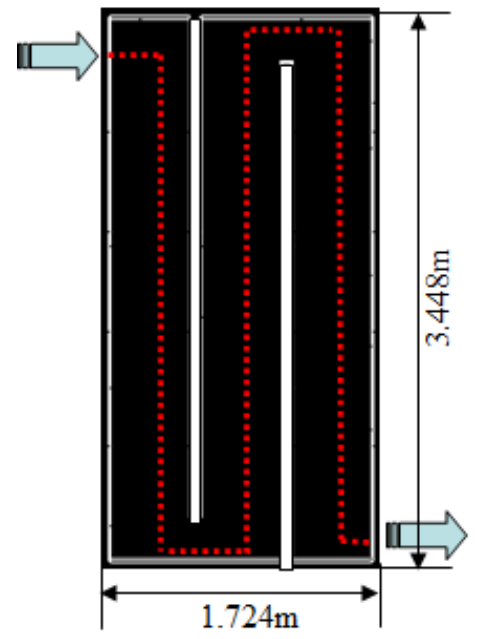

(a)

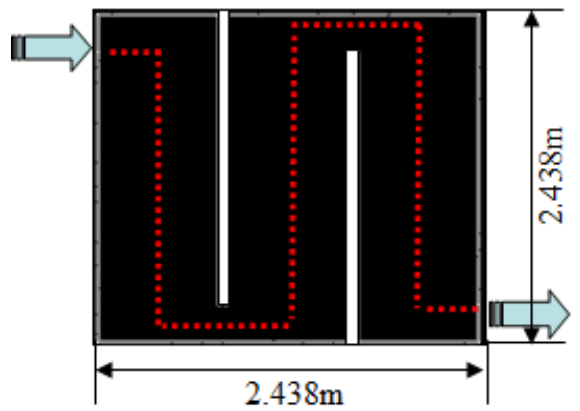

(b)

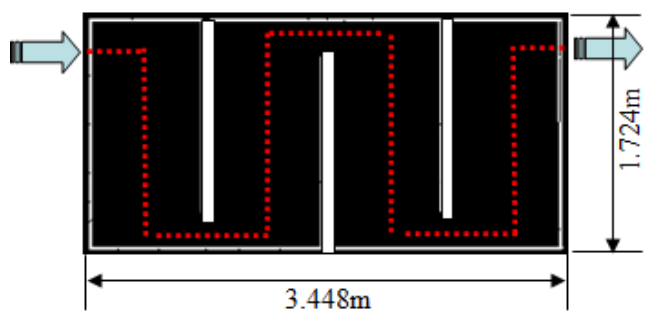

(c)

Figure 2. Schematic plan views of Types I, II, and III: (a) Type I; (b) Type II; (c) Type III.

\subsection{Developing an Internal Short-Circuiting Estimation Method}

We devised an ISI and developed an ISEM based on CFD modelling to analyze local hydrodynamics in a clearwell from the perspective of hydraulic efficiency more systematically. The ISEM is designed to obtain the flow velocity distribution at each section inside a clearwell from the CFD simulation, and to use it to calculate the ISI for estimating short-circuiting and to evaluate the overall hydraulic efficiency of a clearwell. With ISEM, an engineer can identify and pinpoint the location where short-circuiting occurs quickly and modify the clearwell design reasonably. We used a Type III shape with four baffles as an example to illustrate the method.

The ISEM comprises the following six steps.

- $\quad$ Step 1: Simulation of the verified CFD model

In this example, the $\mathrm{LW}$ ratio is 16 , and the estimated $\mathrm{T}_{10} / \mathrm{T}$ value is 0.46 .

- Step 2: Selection sections in each channel zone

As depicted in Figure 3, the area where the water flows parallel to the baffle is called the channel zone, and the remaining part where the direction of the water flow changes by $180^{\circ}$ is called the turning zone.

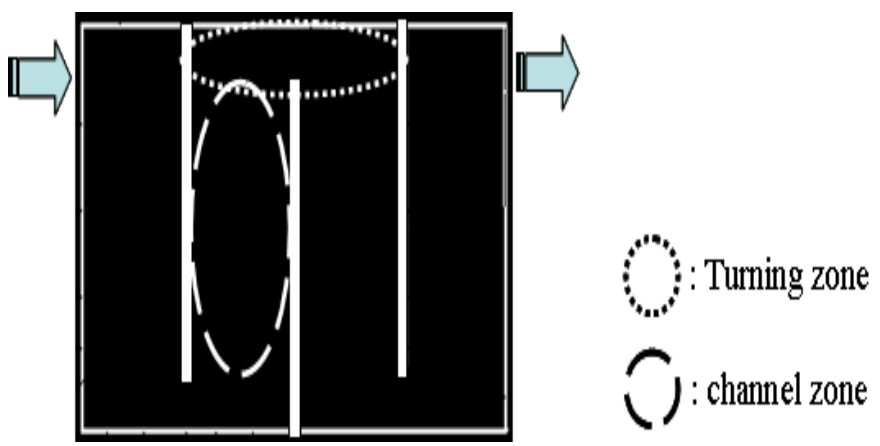

Figure 3. Turning zones and channel zones in the clearwell.

The number and position of the section should be selected to suit the purpose of the analysis. We selected three sections at the starting, middle, and ending points of each channel zone, as depicted in Figure 4 . We considered a total of 15 sections in the example. 


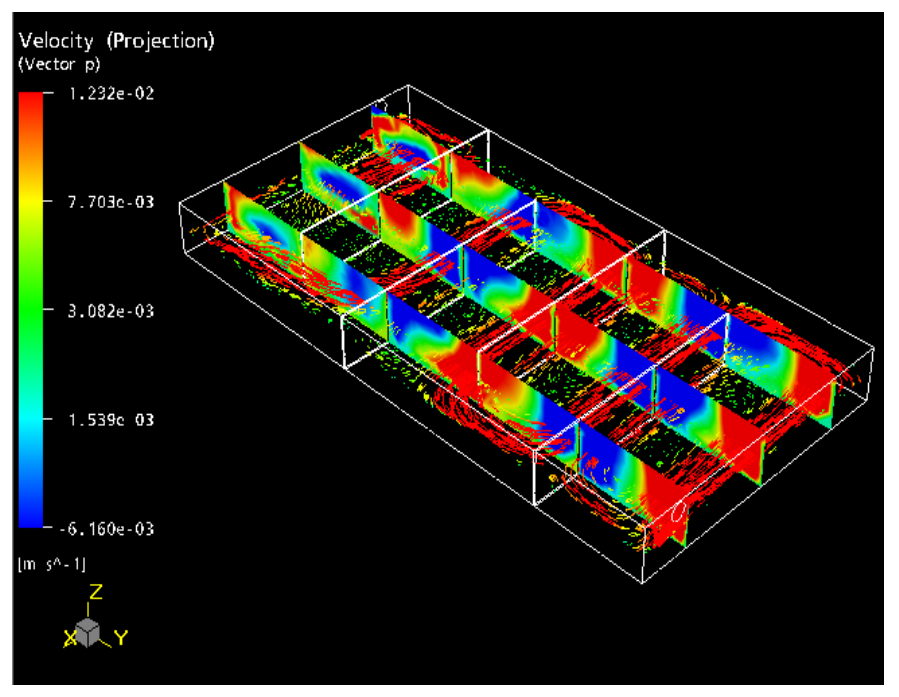

Figure 4. Locations of section in example.

- Step 3: Calculating the average vertical velocity of each element

We divided each section into 60 segments in the direction of gravity and 136 segments in the channel width, thereby resulting in 8160 square elements. We selected this segmentation because the number of elements is sufficient to represent the velocity distribution of the corresponding section. Then, we obtained the average vertical velocity of each element (element velocity) from the CFD simulation.

- Step 4: Converting element velocity data into a frequency-of-occurrence diagram

We converted element velocity data into a frequency-of-occurrence diagram to quantify the number of elements whose velocity is higher than the average velocity of the section. In this histogram, the horizontal axis represents the element velocity, and the vertical axis represents the ratio of the corresponding velocity elements number to the total elements number. Further, the lower $x$ value portion is related to the dead zone or the recirculation zone, and the higher $x$ value is related to the jet flow zone. If the distribution spread is low, the flow pattern at that location is close to the ideal plug flow. However, it can be inferred that, the higher the number of elements than the average velocity of the section is, the more short-circuiting occurs.

A histogram at the middle section of the third channel zone is shown in Figure 5. In this case, the average section velocity is $0.006 \mathrm{~m} / \mathrm{s}$ and the maximum and minimum element velocity are $-0.012 \mathrm{~m} / \mathrm{s}$ and $0.028 \mathrm{~m} / \mathrm{s}$, respectively. The overall distribution is not a bell-shaped curve like the normal distribution; however, it has a bimodal curve where the value in the lower tail and the upper tail is high. 


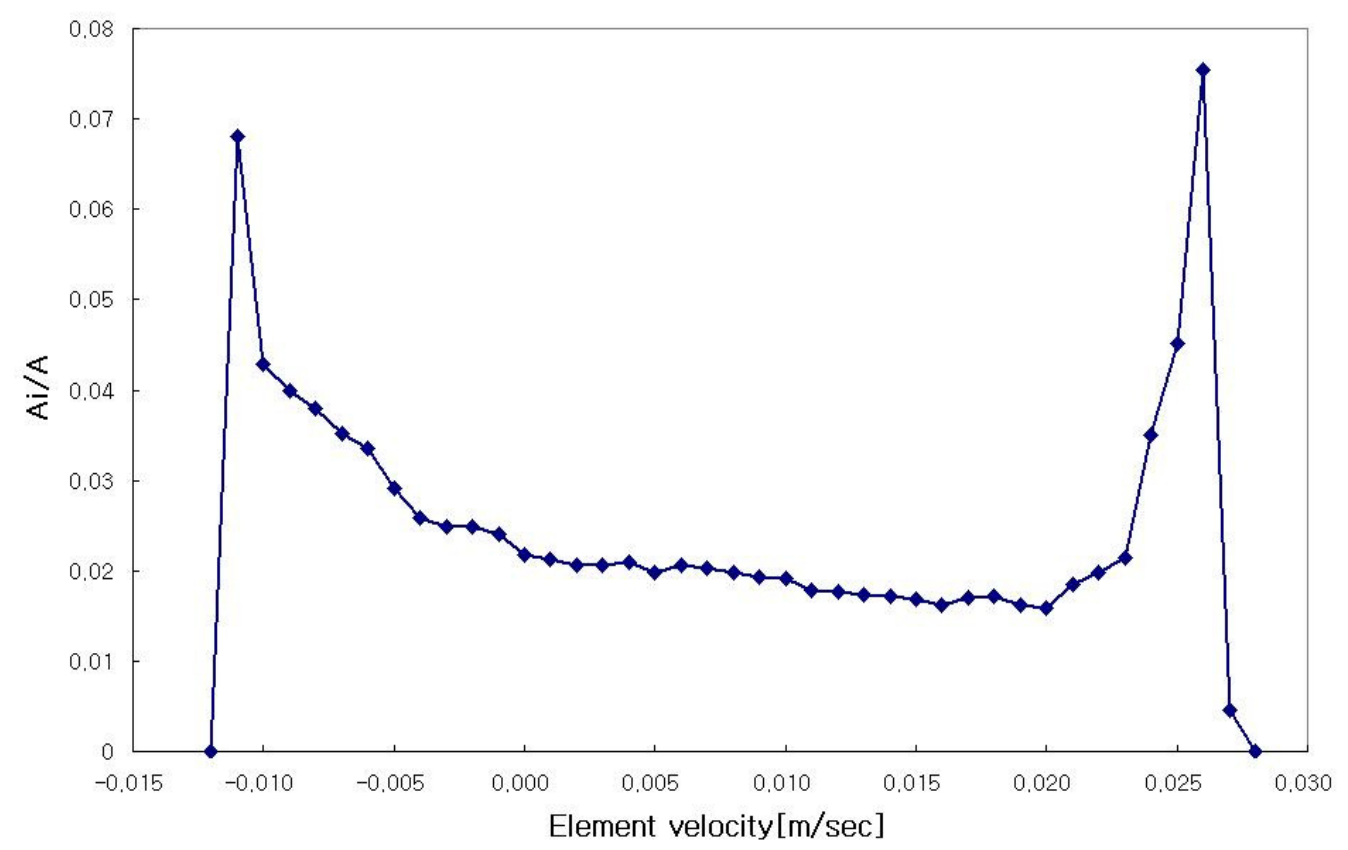

Figure 5. Element velocity distribution at the middle section of the third channel zone.

- Step 5: Calculating ISI for each section

As explained in Equations (4)-(6), we consider three indices as candidates that we refer to as ISI; they reflect the amount of short-circuiting at the corresponding section.

As the short-circuiting grows, the curve of the histogram broadens and the value in the upper tail increases. Therefore, we consider the coefficient of variation as Index A, which is appropriate to represent the spread of the velocity distribution. Indices B and C are designed to analyze the high-velocity portion of the histogram quantitatively. Index $B$ is the ratio of $A_{3 V a v g}$. to $A_{t}$ where $A_{3 V a v g}$. represents the area from three times the average section velocity to infinity value, and $A_{t}$ represents the total area in a frequency-of-occurrence diagram as explained in Equations (7) and (8). Index $C$ denotes the value of $V_{10 \% A}$ divided by $\mathrm{V}_{\text {avg. }} \mathrm{V}_{10 \% \mathrm{~A}}$ represents the 10th percentile velocity as explained in Equation (9) and $\mathrm{V}_{\text {avg. }}$. denotes the average section velocity.

At the middle section of the third channel zone, the values of $\mathrm{V}_{\text {avg., }}, \sigma, \mathrm{A}_{3 \text { Vavg., }}, \mathrm{A}_{t}$, and $\mathrm{V}_{10 \% A}$ are $0.006 \mathrm{~m} / \mathrm{s}, 0.012 \mathrm{~m} / \mathrm{s}, 0.053,0.210$, and $0.025 \mathrm{~m} / \mathrm{s}$, respectively. Therefore, indices $A, B$, and $C$ are $2.00,0.25$, and 4.18 , respectively.

$$
\begin{aligned}
& \text { Index } A=\frac{\sigma}{V_{\text {avg. }},} \\
& \text { Index } B=\frac{A_{3 \operatorname{Vavg} .},}{A_{t}}, \\
& \text { Index } C=\frac{V_{10 \% A}}{V_{\text {avg. }}},
\end{aligned}
$$

where $\sigma, \mathrm{V}_{\text {avg., }}$ and $f(x)$ denote the standard derivative of element velocity distribution, section average velocity, and the dosage function of the histogram, respectively. Further,

$$
\begin{gathered}
A_{3 \text { Vavg. }}=\int_{3 \text { Vavg. }}^{\infty} f(x) d x, \\
A_{t}=\int_{-\infty}^{\infty} f(x) d x, \\
\int_{V_{10 \% A}}^{\infty} f(x) d x=0.1 A_{t} .
\end{gathered}
$$


- $\quad$ Step 6: Plotting the ISI diagram

We plotted indices $\mathrm{A}, \mathrm{B}$, and $\mathrm{C}$ of all sections in the ISI diagram to estimate the local hydraulic dynamics, as shown in Figure 6. In this ISI diagram, the $x$ axis represents $V_{i} / V$, which is the ratio of volume from the inlet up to the corresponding section and the total clearwell volume, whereas the y axis represents indices A, B, and C.

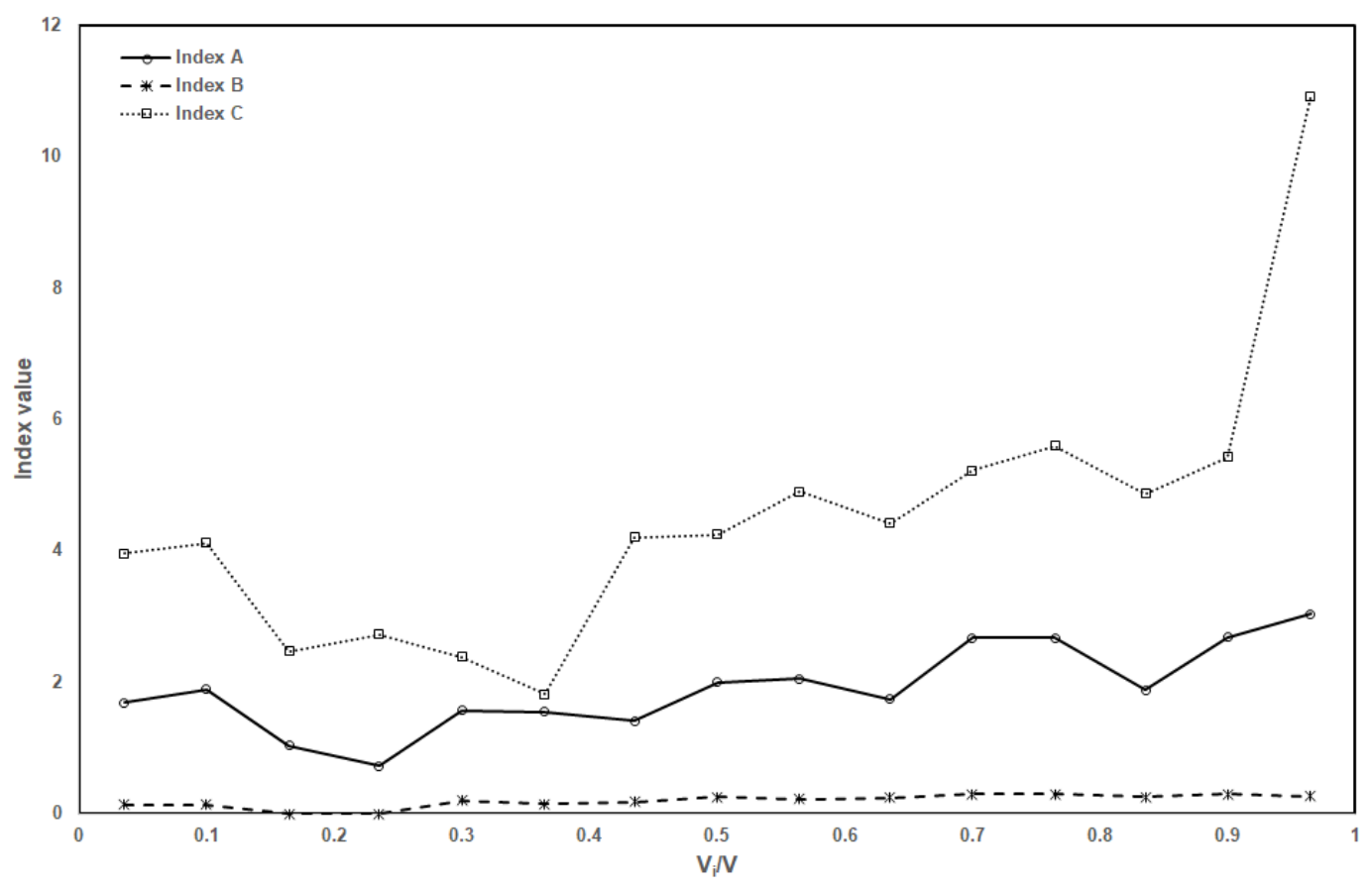

Figure 6. ISI diagram of example case.

$\mathrm{V}_{\mathrm{i}} / \mathrm{V}$ is 0.5 at the middle section of the third channel zone in the example.

\section{Results}

\subsection{CFD Model Verification}

We verified the CFD model from a local hydrodynamics and trace transport point of view. For the former, flow velocity was measured using ADV in the Type III shape with six baffles. A total of 35 points at the 2nd, 3rd, 4 th, and 5 th channel zones from a total of 140 points were considered as the detecting points. Then, the measured velocities were compared to the velocity from the CFD simulation at the same location. The flow pattern of the CFD simulation and the test was very similar, as illustrated in Figure 7. The coefficients of determination $\left(R^{2}\right)$ of the absolute velocity and the angle in the $x-y$ plan were 0.90 and 0.87 , respectively.

Second, the accuracy of the tracer transport of the CFD model was verified by comparing the $\mathrm{T}_{10} / \mathrm{T}$ values from the CFD model and tracer tests in a total of 12 cases. As shown in Figure 8, the $\mathrm{T}_{10} / \mathrm{T}$ value of the CFD simulation was slightly higher than that of the experiment in the range $0.3-0.4$. In the other ranges, the results were very similar and $R^{2}$ was 0.82 . 


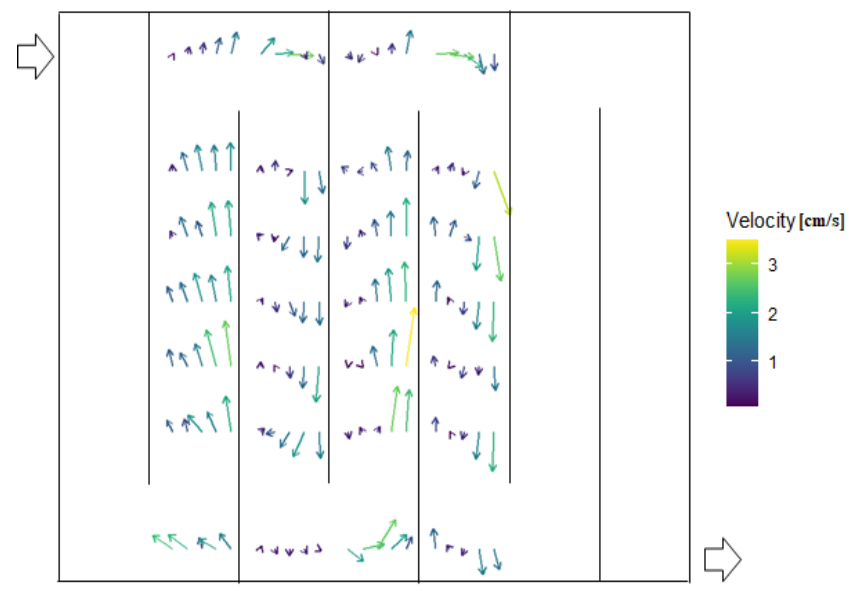

(a)

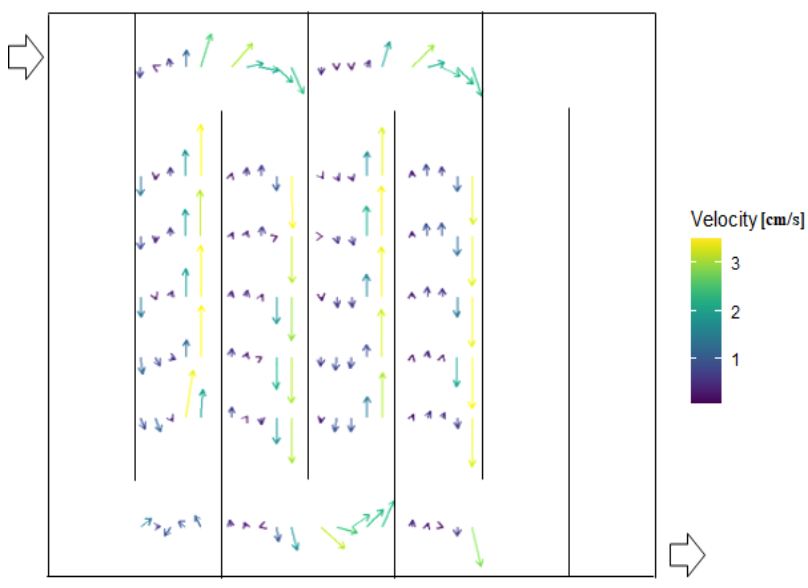

(b)

Figure 7. Local hydraulic dynamics in Type III with 6 baffles: (a) velocity field of experiment; (b) velocity field of CFD simulation.

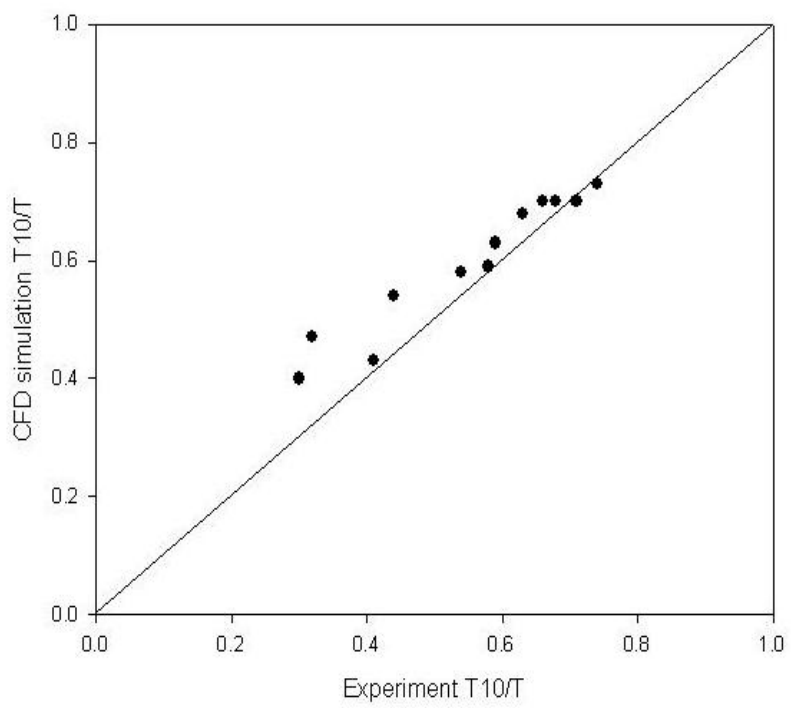

Figure 8. Comparing with $\mathrm{T}_{10} / \mathrm{T}$ values of pilot tests and CFD model.

During normal operation of a clearwell, the flow is generally assumed to be a turbulent flow, and this flow can be handled by most turbulence models. However, in some areas of the clearwell a low Reynolds number flow can exist. Essentially, the fluid in the dead zone can change from turbulent to laminar condition depending on the overall momentum of the incoming jet, clearwell geometry, and inlet geometry. This shift from a fully turbulent to a partially laminar flow regime significantly affects modelling accuracy because the conventional turbulence models cannot accurately capture the flow in the low Reynolds number regime. Even though accurate prediction in the coexistence of laminar, transitional, and turbulent regimes is very challenging, LES can be a promising approach to predict the flow where such complex flows are all present.

\subsection{Determining an ISI}

We compared each average index value with the $\mathrm{T}_{10} / \mathrm{T}$ value in 18 cases of all types of shapes to select the most appropriate ISI among the 3 candidates. We calculated the average index value in each case by integrating the index curve from 0 to 1 in the ISI diagram. Because the index represents short-circuiting at the section, this average index value shows how much short-circuiting occurs in the overall clearwell. Thus, as the pattern 
of $\mathrm{T}_{10} / \mathrm{T}$ and the average index value is close, the index is well suited as ISI. Figure 9 shows that the average index value linearly decreases as the $T_{10} / T$ value increases, and the $R^{2}$ of indices A, B, and C become $0.78,0.51$, and 0.84 , respectively. Thus, we selected index $\mathrm{C}$ as the ISI and applied it to the developed ISEM.

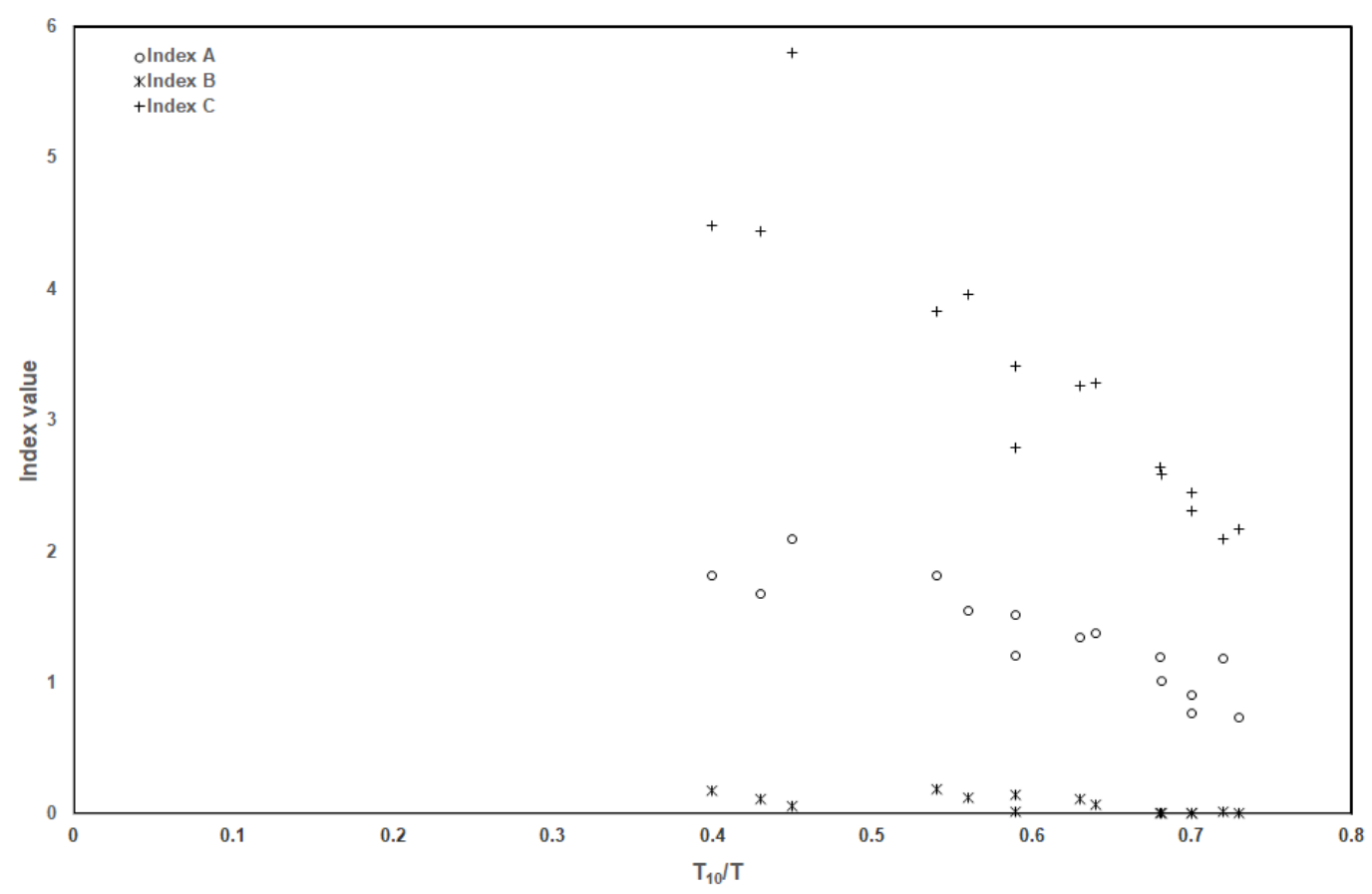

Figure 9. Pattern of indices and $\mathrm{T}_{10} / \mathrm{T}$.

3.3. Estimating the Effect of the LW Ratio on $T_{10} / T$ with ISEM

3.3.1. Estimating Short-Circuiting in Low LW Ratio

Before investigating why the $\mathrm{T}_{10} / \mathrm{T}$ value increases as the $\mathrm{LW}$ ratio increases and spotting the vulnerable locations from a hydraulic efficiency point of view, we derive the pattern between the LW ratio and the $\mathrm{T}_{10} / \mathrm{T}$ in the Type II shape. A total of six cases were simulated with the verified CFD model. The baffle number, $\mathrm{LW}$ ratio, $\mathrm{T}_{10} / \mathrm{T}$, and the average ISI of each case are summarized in Table 3. As shown in Figure 10, the $\mathrm{T}_{10} / \mathrm{T}$ value rapidly increases until the $\mathrm{LW}$ ratio of 36 , and the $\mathrm{T}_{10} / \mathrm{T}$ value over the ratio of 56 diminishes and converges at about 0.7 . In addition, the average ISI, which represents the overall short-circuiting occurrence, shows no further decline in the LW ratio range after 36 .

Table 3. Number of baffles, $\mathrm{LW}$ ratio, $\mathrm{T}_{10} / \mathrm{T}$, and average ISI in Type II.

\begin{tabular}{cccc}
\hline Number of Baffles & LW Ratio & $\mathbf{T}_{\mathbf{1 0}} / \mathbf{T}$ & Average ISI \\
\hline 2 & 9 & 0.45 & 5.80 \\
3 & 16 & 0.56 & 3.95 \\
4 & 25 & 0.64 & 3.28 \\
5 & 36 & 0.70 & 2.31 \\
6 & 49 & 0.72 & 2.10 \\
7 & 63 & 0.72 & 2.09 \\
\hline
\end{tabular}




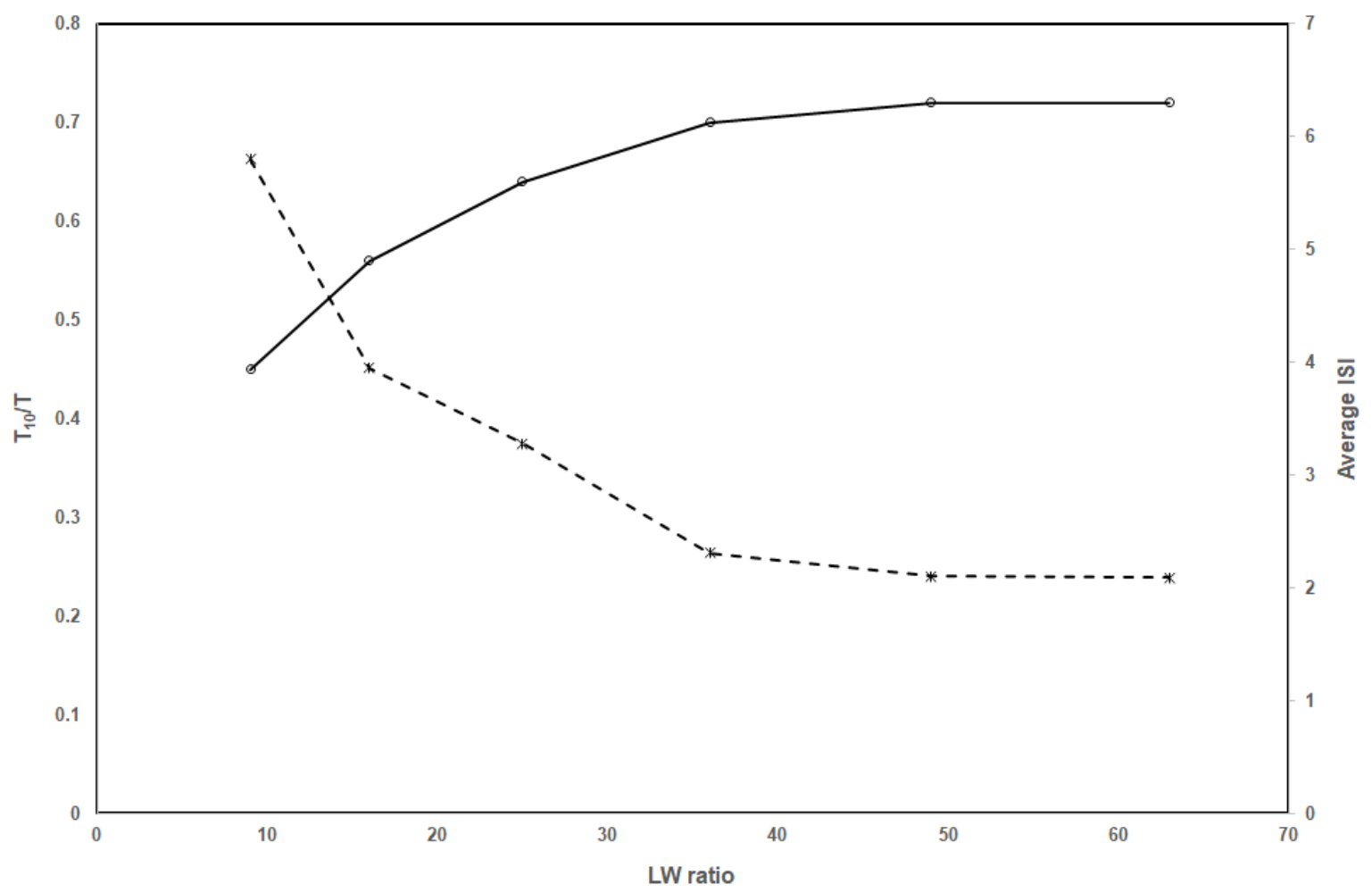

Figure 10. Pattern of $\mathrm{LW}$ ratio and $\mathrm{T}_{10} / \mathrm{T}$ and $\mathrm{LW}$ ratio and average ISI in Type II.

We applied the ISEM to Type II with three baffles to estimate short-circuiting in a low $\mathrm{LW}$ ratio case where the $\mathrm{T}_{10} / \mathrm{T}$ value has not converged to the maximum. The $\mathrm{LW}$ ratio is 16 , and the $\mathrm{T}_{10} / \mathrm{T}$ value is 0.56 in this case. In applying ISEM, we consider three sections in each channel zone, which results in a total of 12 sections; each section comprised an element of 8160 . Owing to the three baffles, the inside of the clearwell is divided into four categories: an influent zone, effluent zone, four channel zones, and three turning zones. The $\mathrm{V}_{\mathrm{i}} / \mathrm{V}$ of the influent zone is close to 0 , and that of the effluent zone is close to 1 . The $\mathrm{V}_{\mathrm{i}} / \mathrm{V}$ of the channel zones is $0-0.23,0.27-0.48,0.52-0.73$, and $0.77-1$ in the ISI diagram, while the remaining portion of the clearwell includes the turning zones.

Figure 11 shows that the ISI at the influent and effluent zones is higher than those of the channel and turning zones. The ISI value is the highest at 7.61 at the effluent zone and the second highest at 4.90 at the influent zone. The higher ISI values are attributed to the direction of the water flow at the inlet, and the outlet is perpendicular to the direction of the water flow at the channel zone; the area of the inlet and outlet is smaller than the sectional area at the channel section. Further, the ISI increased as $V_{i} / V$ increased in the second $\left(\mathrm{V}_{\mathrm{i}} / \mathrm{V}=0.27-0.48\right)$, third $\left(\mathrm{V}_{\mathrm{i}} / \mathrm{V}=0.52-0.73\right)$, and fourth $\left(\mathrm{V}_{\mathrm{i}} / \mathrm{V}=0.77-1\right)$ channel zones. This phenomenon is attributed to the formation of several moderately sized recirculation zones where the direction of flow is opposite to that of the main flow and the dead zones at the latter part of each channel zone. In addition, the ISI at all turning zones $\left(\mathrm{V}_{\mathrm{i}} / \mathrm{V}=0.23-0.27\right.$, $0.48-0.52$, and $0.73-0.77$ ) barely changes and is strongly affected by the ISI of the front channel zone. Thus, the ISI values at the influent and effluent zones are high, and the point $\left(\mathrm{V}_{\mathrm{i}} / \mathrm{V}=0.27\right)$ between the upstream and midstream has the lowest ISI value. After that point, the ISI value increases as $\mathrm{V}_{\mathrm{i}} / \mathrm{V}$ increases. Therefore, the ISI curve has a " $\mathrm{V}$ " shape in the low LW ratio. This implies that, in the low LW ratio case, a large amount of short-circuiting can be reduced by changing the inlet and outlet shapes, modifying the baffle arrangement, or using turning vanes at the upstream and downstream areas in the clearwell. 


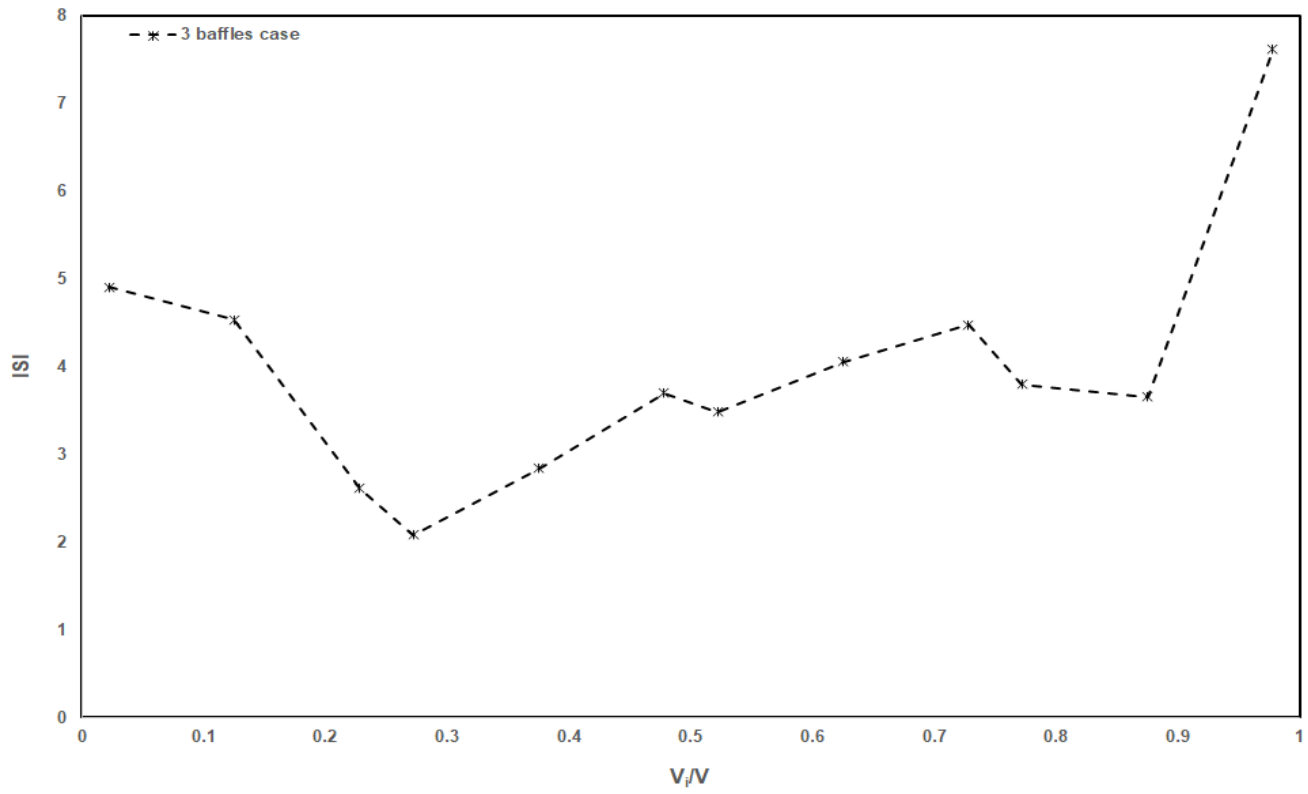

Figure 11. ISI diagram in Type II case with a LW ratio of 16.

\subsubsection{Investigating Why the $T_{10} / T$ Value Increases as $L W$ Ratio Increases}

Figure 12 shows the ISI diagram of the 2, 3, 4, and 5 baffle cases of Type II to investigate why the $\mathrm{T}_{10} / \mathrm{T}$ value increases as the $\mathrm{LW}$ ratio increases. As the $\mathrm{LW}$ ratio increases, the ISI values at the inlet gradually decrease from 8.46 in the 2 baffles case to 4.32 in the 5 baffles case. We identify similar phenomena at the outlet, with ISI values reduced from 10.48 in the 2 baffles case to 3.90 in the 5 baffles case. Flow straightening caused by the inlet and outlet is prevented because the distance between channels narrows and the relative inlet and outlet areas increase by comparison with the channel area. Thus, the velocity differential is diminished and the short-circuiting is prevented. In the 5 baffles case where the $T_{10} / T$ value approaches maximum value, the ISI of the influent and effluent zones are still higher than that of the channel and turning zones. This indicates that the effect of the inlet and outlet on short-circuiting still exists although the effect reduces as the LW ratio increases.

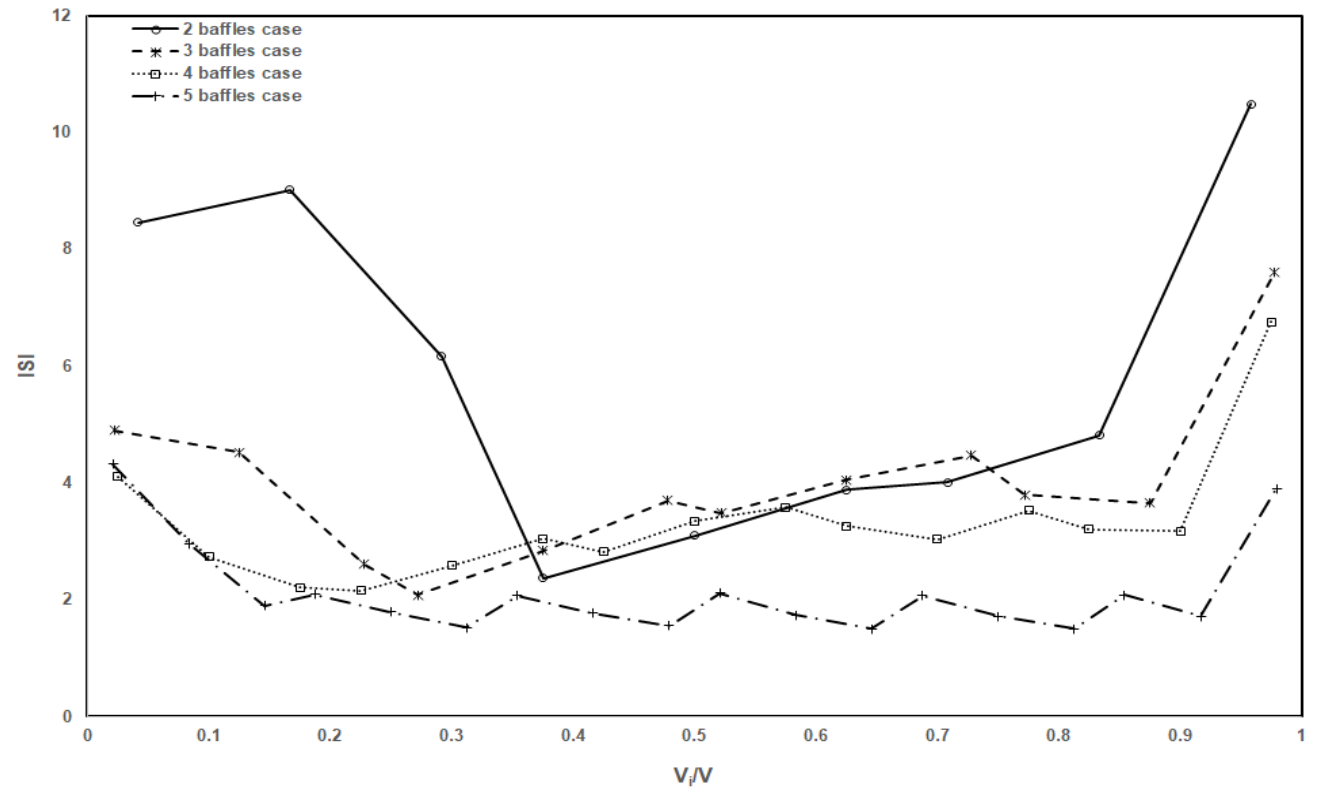

Figure 12. ISI diagram in the 2, 3, 4, and 5 baffles cases. 
The ISI of the 2,3 , and 4 baffles cases, where the $\mathrm{T}_{10} / \mathrm{T}$ value does not converge to the maximum, is the lowest in a Vi/V range of 0.23 to 0.29 . The ISI curves of these cases are therefore $\mathrm{V}$ shaped. However, the increment of ISI per increment of $V_{i} / V$, which represents the ISI curve slope, is declined and converges 0 at a same channel zone as the LW ratio increases because the recirculation and dead zones are reduced as the distance between the baffles closes. Thus, the shape of the ISI curve changes from V shaped to U shaped, where the ISI at the influent and effluent zones is still high; the ISI value is low and remains unchanged in a $V_{i} / V$ range of 0.1 to 0.9 , as the $T_{10} / T$ value converges to the maximum value (i.e., baffles case). From these results, we conclude that short-circuiting at the influent and effluent zones and the midstream and downstream portions of a clearwell are reduced as the LW ratio increases.

After the $\mathrm{T}_{10} / \mathrm{T}$ value converges to the maximum when the $\mathrm{LW}$ ratio is over 36 , the ISI of the middle and downstream portions do not decrease below the limit value. Further, the ISI is unchanged at the influent and effluent zones. This implies that there is a limit to improving the $\mathrm{T}_{10} / \mathrm{T}$ value using only baffles because some recirculation and dead zones still exist beyond the critical LW ratio. It is therefore assumed that another device such as a turning vane or diffuser wall should be used to improve $\mathrm{T}_{10} / \mathrm{T}$ after the $\mathrm{LW}$ ratio exceeds the critical value.

\subsection{Estimating the Effect of Shape on the Pattern of $L W$ Ratio and $T_{10} / T$ \\ 3.4.1. Pattern of LW Ratio and $\mathrm{T}_{10} / \mathrm{T}$ with Different Shape Ratio}

We simulated three different forms of clearwell to analyze the effect of the clearwell shape on the pattern of the $\mathrm{LW}$ ratio and $\mathrm{T}_{10} / \mathrm{T}$. A shape factor was applied to represent a rectangular clearwell numerically; the horizontal length was divided by the vertical length in a floor plan. Therefore, the shape ratio of Types I, II, and III are $0.5,1$, and 2, respectively. The smaller the shape ratio, the larger is the channel zone in clearwell than the turning zone. For a low shape ratio, each channel zone has a relatively long length. Further, the shape ratio of 1 indicates that the form of the clearwell is a square.

Figure 13 shows that Types I and II curves are very close; however, the curve of Type III is distinct from the other two curves. The difference of 0.10 occurs in a range of the LW ratio of 25 to 35 and the maximum $\mathrm{T}_{10} / \mathrm{T}$ values are similar to about 0.7 . These results conclude that, as the shape ratio becomes larger than 1, the pattern of the LW ratio and $\mathrm{T}_{10} / \mathrm{T}$ is affected by the shape. However, the maximum $\mathrm{T}_{10} / \mathrm{T}$ is not affected. In addition, there is a difference between the critical $\mathrm{LW}$ ratios at which the $\mathrm{T}_{10} / \mathrm{T}$ value converges for different shapes. The $\mathrm{T}_{10} / \mathrm{T}$ value stays almost the same over an $\mathrm{LW}$ ratio of 34 in Type I, over 36 in Type II, and over 56 in Type III.

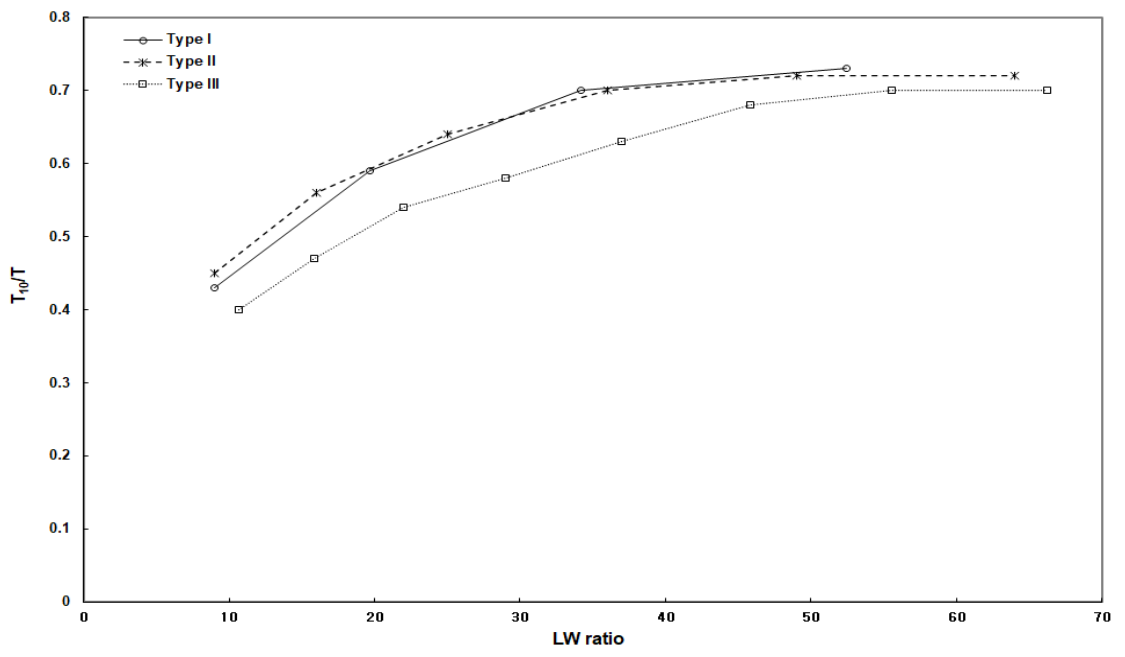

Figure 13. Pattern of the LW ratio and $\mathrm{T}_{10} / \mathrm{T}$ in Types I, II, and III case. 


\subsubsection{Investigating the Effect of Shape on the Pattern of the LW Ratio and $\mathrm{T}_{10} / \mathrm{T}$}

Using the developed ISEM, we investigated factors that affect the pattern of the $\mathrm{LW}$ ratio and $\mathrm{T}_{10} / \mathrm{T}$ for differing clearwell shapes. It is challenging to compare three ISI diagrams of Types I, II, and III with the same LW ratio because of their shape discrepancy. Therefore, we compared three ISI diagrams with similar LW ratios in the range 25-35, where the maximum difference of the $\mathrm{T}_{10} / \mathrm{T}$ value occurs. The type, shape ratio, baffle numbers, $\mathrm{LW}$ ratio, $\mathrm{T}_{10} / \mathrm{T}$ value, and average ISI of the comparison cases are presented in Table 4 . The $\mathrm{T}_{10} / \mathrm{T}$ of Type I converges to the maximum value of 0.70 ; however, the other cases do not reach the hydraulic optimum. The LW ratio of Type II is slightly smaller than those of Types I and III. Therefore, we assume that the ISI value of Type II in Figure 14 is a little overestimated compared with the same LW ratio case.

Table 4. Type, shape ratio, number of baffles, $\mathrm{LW}$ ratio, $\mathrm{T}_{10} / \mathrm{T}$, and average ISI of the comparison cases.

\begin{tabular}{cccccc}
\hline Type & Shape Ratio & Number of Baffles & LW Ratio & $\mathbf{T}_{\mathbf{1 0}} / \mathbf{T}$ & Average ISI \\
\hline Type I & 0.5 & 3 & 34 & 0.70 & 2.45 \\
Type II & 1 & 4 & 25 & 0.64 & 3.28 \\
Type III & 2 & 7 & 37 & 0.59 & 3.42 \\
\hline
\end{tabular}

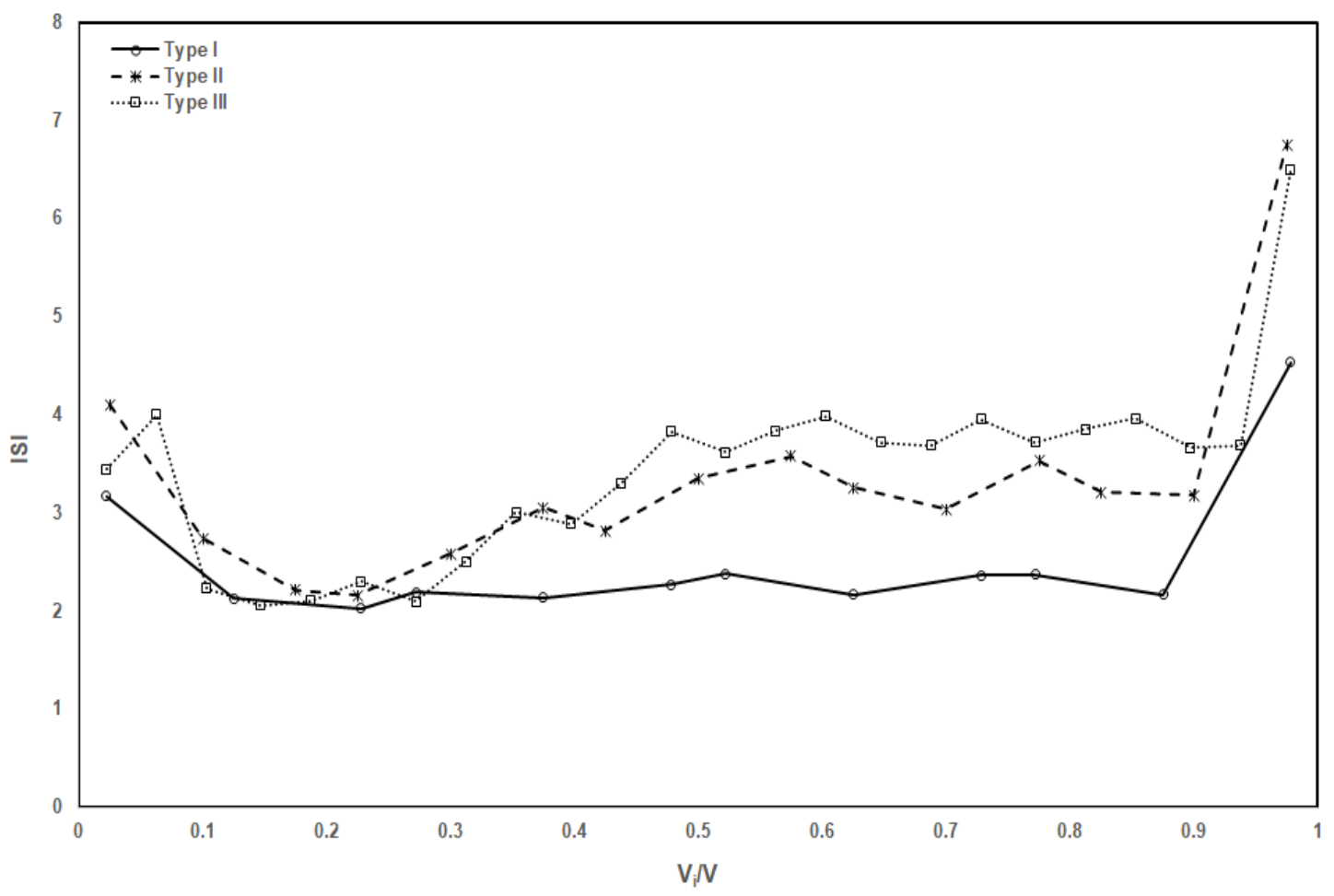

Figure 14. ISI diagram in Types I, II, and III cases.

The ISI values of Types I (3.17), II (4.11), and III (3.44) were similar at the influent zone, and we found it difficult to correlate the influent zone and short-circuiting with a different shape ratio. This result is expected because the geometry and flow conditions are similar despite shape differences near the inlet. However, the ISI values were different in the effluent zone. Type I where $\mathrm{T}_{10} / \mathrm{T}$ converged to the maximum has the lowest ISI value of 4.53. The ISI values for Types II and III were 6.75 and 6.50, respectively, which indicates similar high values. Type I had the constant ISI value in the channel and turning zones, however Types II and III showed a slight increment of ISI as $\mathrm{V}_{\mathrm{i}} / \mathrm{V}$ increased in the channel zones. Therefore, the ISI curves of Types I, II, and III were very close in the 
upstream portion, and the difference between the ISI values occurred in the midstream and downstream. From these results we conclude that as the shape ratio decreases, the portion of the turning zone increases, and therefore, a significant boundary separation is generated. These results suggest that the midstream and downstream of the clearwell are the affected portions because their shapes are different.

\section{Discussion}

In this study, we simulated and analyzed 18 cases with different LW ratios and shapes. We highlighted the interesting findings as follows.

By implementing ISEM, we analyzed the effect of the baffle configuration on hydraulic efficiency. With the verified CFD model, we can identify that the $\mathrm{T}_{10} / \mathrm{T}$ value increased as the $\mathrm{LW}$ ratio increased, and the $\mathrm{T}_{10} / \mathrm{T}$ value converged to the maximum value after the critical LW ratio was reached. The ISI values of the influent and effluent zones rapidly reduced, and the recirculation and dead zones reduced in the channel zone as the LW ratio increased. Therefore, as the $\mathrm{T}_{10} / \mathrm{T}$ value converged to the maximum value, the ISI curve changed from $\mathrm{V}$ shaped to $\mathrm{U}$ shaped. Hydraulic efficiency was especially improved in the influent zone, effluent zone, and in the midstream and downstream of the channel and turning zones. After reaching the critical LW ratio, the ISI curve was unchanged, and the $\mathrm{T}_{10} / \mathrm{T}$ value stayed almost constant. Therefore, it seems that there is a limit to the extent to which $\mathrm{T}_{10} / \mathrm{T}$ values can be improved using only baffles.

We studied the effect of the clearwell shape on the pattern of the $\mathrm{LW}$ ratio and $\mathrm{T}_{10} / \mathrm{T}$. The larger the shape ratio, the smaller is the $\mathrm{T}_{10} / \mathrm{T}$ value at the same $\mathrm{LW}$ ratio. For a range of the LW ratio of 25 to 35 , the maximum difference of $\mathrm{T}_{10} / \mathrm{T}$ of 0.10 occurs based on the shapes. Further, as the shape ratio becomes larger than 1 , the $\mathrm{T}_{10} / \mathrm{T}$ value is affected by the shape. This phenomenon indicates that the proportion of the turning zone increases, and the length of each channel zone decreases as the shape ratio increases. Therefore, a significant boundary separation is generated later in each channel zone. In addition, we can observe a difference in short-circuiting at the middle and downstream.

\section{Conclusions}

This study intended to develop a novel hydraulic efficiency estimation method (i.e., ISEM) and propose an index (i.e., ISI) that can be applied to evaluate short-circuiting in a clearwell. Existing HEIs (e.g., $\mathrm{T}_{\mathrm{i}}, \mathrm{T} 10, \mathrm{~T}_{\mathrm{p}}, \mathrm{T}_{\mathrm{g}}, \mathrm{T}_{10} / \mathrm{T}$ ) are suitable for assessing the overall hydraulic efficiency of a clearwell. However, implementing HEIs originating from RTD curve cannot represent internal hydraulics. The ISEM demonstrated that it could overcome the shortcomings of existing HEIs and quantify short-circuiting at any point within clearwell using ISI. The ISEM can also be applied under various clearwell conditions such as shape, baffle configuration, inlet, and outlet characteristics, or the presence or absence of a turning vane or a diffuser wall with CFD modelling. The application of ISEM to various cases allowed the conclusion that the approach was an effective method for evaluating hydraulic efficiency inside a clearwell, and the approach is expected to enable engineers to design clearwells to identify the vulnerable locations and optimize the disinfection ability. In this study, we implemented a turbulent model. However, the flow was laminar in some domains. So, there was a drawback that we had slightly overpredicted the turbulence. In a future study, we should detect the transition points and applied suitable models to improve the accuracy. Furthermore, the CFD model can be combined with machine learning techniques to extract knowledge for reducing the computational cost.

Author Contributions: Conceptualization, E.S. and H.P.; methodology, E.S.; formal analysis, E.S. and J.R.; writing — original draft preparation, E.S.; writing—review and editing, H.P.; visualization, J.R.; supervision, H.P. All authors have read and agreed to the published version of the manuscript. 
Funding: This research was funded by Basic Science Research Program through the National Research Foundation of Korea (NRF), grant number 2018R1D1A1B07050208 and Disaster-Safety Platform Technology Development Program of the NRF, grant number 2019M3D7A1095629.

Institutional Review Board Statement: Not applicable.

Informed Consent Statement: Not applicable.

Conflicts of Interest: The authors declare no conflict of interest.

\section{References}

1. American Water Works Association. Water Quality and Treatment: A Handbook of Community Water Supplies; American Water Works Association: Denver, CO, USA, 1990.

2. Marske, D.M.; Boyle, J.D. Chlorine contact chamber design—A field evaluation. Water Sew. Work. 1973, 120, 70-71.

3. Falconer, R.A.; Tebbutt, T.H.Y. A theoretical and hydraulic model study of a chlorine contact tank. Proc. Inst. Civ. Eng. Part 2 Res. Theory 1986, 81, 255-276.

4. Stamou, A.I. Verification and application of a mathematical model for the assessment of the effect of guiding walls on the hydraulic efficiency of chlorination tanks. J. Hydroinform. 2002, 4, 245-254. [CrossRef]

5. Stambolieva, A. Methods for the Design of Chlorine Contactors for Drinking Water Treatment. In Proceedings of the 1993 AWWA Annual Conference, San Antonio, TX, USA, 6-10 June 1993.

6. Hannoun, I.A.; Boulos, F. Optimizing distribution storage water quality: A hydrodynamic approach. J. Am. Water Work. Assoc. 1998, 90, 77-87. [CrossRef]

7. Wang, H.; Falconer, R.A. Simulating disinfection process in chlorine contact tanks using various turbulence models and high-order accurate difference schemes. Water Res. 1998, 32, 1529-1543. [CrossRef]

8. Corzes, G.F.; Hagstrom, J.P.; Clark, M.M.; Ducoste, J.; Burns, C. Improving Clearwell Design for CT Compliance; AWWARF and AWWA: Denver, CO, USA, 1999.

9. Huang, T.H.; Brouckaert, C.J. Application of computational fluid dynamics modeling to an ozone contactor. Water SA 2004, 30, 51-56. [CrossRef]

10. Hofman, J.; Wind, D.; Wols, B.; Uijttewaal, W. The Use of CFD Modeling to Determine the Influence of Residence Time Distribution on the Disinfection of Drinking Water in Ozone Contactors. In Proceedings of the COMSOL Conference, Napoli, Italy, 23-24 October 2007.

11. Wols, B.A.; Uijttewaal, W.S.J.; Rietveld, L.C.; Stelling, G.S.; van Dijk, J.C.; Hofman, J.A.M.H. Residence time distributions in ozone contactors. Ozone Sci. Eng. 2008, 30, 49-57. [CrossRef]

12. Kim, D.; Kim, D.I.; Kim, J.H.; Stoesser, T. Large eddy simulation of flow and tracer transport in multichamber ozone contactors. J. Environ. Eng. 2010, 136, 22-31. [CrossRef]

13. Amini, R.; Taghipour, R.; Mirgolbabaei, H. Numerical assessment of hydrodynamic characteristics in chlorine contact tank. Int. J. Numer. Methods Fluids 2011, 67, 885-898. [CrossRef]

14. Zhang, J.; Tejada-Martinez, A.E.; Zhang, Q. Hydraulic efficiency in RANS of the flow in multi-chambered ozone contactors. J. Hydraul. Eng. 2013, 139, 1150-1157. [CrossRef]

15. Chiu, K.; Lyn, D.A.; Savoye, P.; Blatchley, E.R., III. Integrated UV disinfection model based on particle tracking. ASCE J. Environ. Eng. 1999, 125, 7-16. [CrossRef]

16. Lyn, D.A.; Chiu, K.; Blatchley, E.R. Numerical modeling of flow and disinfection in UV disinfection channels. ASCE J. Environ. Eng. 1999, 125, 17-26. [CrossRef]

17. Do-Quang, Z.; Cockx, A.; Line, A.; Roustan, M. Computational fluid dynamics applied to water and wastewater treatment facility modeling. Environ. Eng. Policy 1999, 1, 137-147. [CrossRef]

18. Greene, D.J.; Farouk, B.; Haas, C.N. CFD design approach for chlorine disinfection processes. J. Am. Water Work. Assoc. 2004, 96, 138-150. [CrossRef]

19. Zhang, G.; Lin, B.; Falconer, R.A. Modelling disinfection by-products in contact tanks. J. Hydroinform. 2000, 2, 123-132. [CrossRef]

20. Bolanos, E.Q.; Ocampo, J.T.; Rodriguez, L.C. Applicability of computational fluid dynamics to simulate ozonation processes. Ing. Desarro. 2008, 24, 97-116.

21. Bartrand, T.A.; Farouk, B. Countercurrent gas/liquid flow and mixing: Implications for water disinfection. Int. J. Multiph. Flow 2009, 35, 171-184. [CrossRef]

22. Wols, B.A.; Hofman, J.A.M.H.; Uijttewaal, W.S.J.; Rietveld, L.C.; van Dijk, J.D. Evaluation of different disinfection calculation methods using CFD. Environ. Model. Softw. 2010, 25, 573-582. [CrossRef]

23. Talvy, S.; Debaste, F.; Martinelli, L.; Chauveheid, E.; Haut, B. Development of a tool, using CFD, for the assessment of the disinfection process by ozonation in industrial scale drinking water treatment plants. Chem. Eng. Sci. 2011, 66, 3185-3194. [CrossRef]

24. Angeloudis, A.; Stoesser, T.; Gualtieri, C.; Falconer, R.A. Contact tank design impact on process performance. Environ. Model. Assess. 2016, 21, 563-576. [CrossRef] 
25. Wang, H.; Shao, X.; Falconer, R.A. Flow and transport simulation models for prediction of chlorine contact tank flow-through curves. Water Environ. Res. 2003, 75, 455-471. [CrossRef] [PubMed]

26. Rauen, W.B.; Lin, B.; Falconer, R.A.; Teixeira, E.C. CFD and experimental model studies for water disinfection tanks with low Reynolds number flows. Chem. Eng. J. 2008, 137, 550-560. [CrossRef]

27. Angeloudis, A.; Stoesser, T.; Falconer, R.A. Predicting the disinfection efficiency range in chlorine contact tanks through a CFD-based approach. Water Res. 2014, 60, 118-129. [CrossRef] [PubMed]

28. Zhang, J.; Tejada-Martinez, A.E.; Zhang, Q.; Lei, H. Evaluating hydraulic and disinfection efficiencies of a full-scale ozone contactor using a RANS-based modeling framework. Water Res. 2014, 52, 155-167. [CrossRef]

29. Demirel, E.; Aral, M.M. Unified analysis of multi-chamber contact tanks and mixing efficiency evaluation based on vorticity field. Part I: Hydrodynamic analysis. Water 2016, 8, 495. [CrossRef]

30. Wu, J.; Xiao, H.; Paterson, E. Physics-informed machine learning approach for augmenting turbulence models: A comprehensive framework. Phys. Rev. Fluids 2018, 3, 074602. [CrossRef]

31. Zhao, Y.; Akolekar, H.D.; Weatheritt, J.; Michelassi, V.; Sandberg, R.D. RANS turbulence model development using CFD-driven machin learning. J. Comput. Phys. 2020, 411, 109413. [CrossRef]

32. Teixeria, E.D.; Siqueira, R.N. Performance assessment of hydraulic efficiency indexes. J. Environ. Eng. 2008, 134, 851-859. [CrossRef]

33. Gualtieri, C. Discussion of "performance assessment of hydraulic efficiency indexes" by Edmilson Costa Teixeira and Renato do Nascimento Siqueira. J. Environ. Eng. 2010, 134, 851-859. [CrossRef] 